
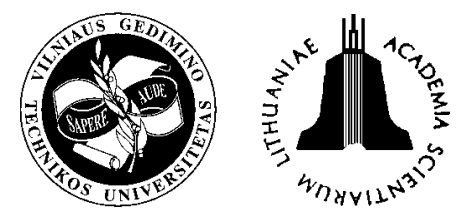

\title{
MAINTENANCE COSTS OF ROAD PAVEMENT AND MOTOR VEHICLES ON THE ROUTE VILNIUS - KAUNAS - KLAIPĖDA
}

\author{
Dainius Miškinis ${ }^{1}$, Vytautas Lingaitis ${ }^{2}$ \\ ${ }^{1}$ Department of Road, E-mail dainius.miskinis@lra.lt \\ ${ }^{2}$ Department of Finance Engineering, E-mail vytautas.lingaitis@lra.lt \\ Vilnius Gediminas Technical University, Sauletekio al. 11, LT-10223 Vilnius, Lithuania
}

Received 1 December 2006; accepted 28 March 2006

\begin{abstract}
The article describes the impact of axle loads of vehicles on the road pavement. Pavement deterioration intensity and the charge imposed on vehicles the axle load of which exceeds the set norm are analyzed on the road under investigation according to the results of weighing axle loads of vehicles as well as appropriate calculation methodologies. The work presents regressive equations according to which maintenance costs of vehicles can be predicted taking the condition of pavement into consideration.
\end{abstract}

Keywords: road pavement, vehicle, maintenance costs.

The deterioration of road pavement is caused by various factors, including climatic conditions, car braking and speeding as well as the use of studded tyres. However, the strongest effect is produced by a varying load on the vehicle axle, especially when the allowable load is exceeded.

Since the weight of the transported goods has been constantly growing and more advanced technologies have been developed, car manufacturers began to make vehicles with $115 \mathrm{kN}$ axle load. The increased load on the road, which has grown from 100 to $115 \mathrm{kN}$, posed some problems to road designers and road maintenance enterprises.

On the other hand, the worsening condition of road pavement causes the deterioration of vehicles, as well as increases fuel consumption and air pollution by the vehicles.

The quality of road pavement may be defined by PSI (Present serviceability index) which is calculated in the following way [1]:

$$
\begin{aligned}
& P S I=5,03-1,91 \log (1+S V)- \\
& -0,01 \sqrt{(C+P)}-0,00214 R D,
\end{aligned}
$$

where $C$ is heavily cracked pavement area, $\mathrm{m}^{2} / 1000 \mathrm{~m}^{2} ; P$ denotes road patches, $\mathrm{m}^{2} / 1000 \mathrm{~m}^{2} ; R D$ is the depth of an average rut, $\mathrm{mm} ; S V$ is the average variation of the road band gradient.

$$
S V=\frac{\sum_{n-1}^{n}\left(x_{i}-x_{m}\right)^{2}}{n-1},
$$

where $x_{i}$ is the real gradient; $x_{m}$ is the average gradient and $n$ is the number of measured gradients.

The data of the deterioration of various kinds of pavement (of different thickness and structure) under a varying axle load are obtained. For the preliminary data analysis, the 4 th power equation (3) is used [1]:

$$
\left(\frac{P_{x}}{P_{y}}\right)^{4}=\frac{N_{y}}{N_{x}},
$$

where $P_{x}$ and $P_{y}$ are axle loads; $N_{x}$ and $N_{y}$ mean the total number of axle loads.

The fourth power index means that with a twofold increase of the axle load the loading effect on pavement is increased sixteen-fold.

Since the road pavement on the route considered differs in thickness and subgrade structure, the power index 4 is used in calculations. Let us calculate the damage to the road pavement based on the technique used in Illinois road testing [2]. The effect of one axle on the road pavement starts to grow rapidly when the load of $80 \mathrm{kN}$ is exceeded. The relationship is expressed as follows: 


$$
E S A=\sum_{n}\left(\frac{A_{i}}{80}\right)^{k_{d . s .}},
$$

where $E S A$ stands for equivalent standard axles; $A_{i}$ is the axle load of a vehicle $(\mathrm{kN}) ; 80$ is a standard axle load, $\mathrm{kN} ; n$ is the number of axles; $k_{d . s .}$ is power index showing the thickness and structure of the pavement.

$E S A$ is an indicator of the effect produced on road pavement showing how the damage made by a particular vehicle axle on road pavement differs from that caused by a standard axle $(80 \mathrm{kN})$. The maximum axle load on Lithuanian roads was designed to be $100 \mathrm{kN}$. However, when Lithuania became an independent state, the need for increasing the allowable load up to $115 \mathrm{kN}$ (the European standard) arose because heavier vehicles could cross Lithuanian borders.

The axle of any weight may be expressed as ESA to show how much more damage is made to the road by the actual axle weight.

The results of weighing obtained in March-December, 2005 on the road Vilnius-KaunasKlaipeda [3] showed that:

- About 6014 thous. of vehicles, including 1225 thous. trucks, passed the weighing station.

- The total number of overloaded vehicles made $16,9 \%$ (206 thous. of vehicles) of all trucks.

- The number of trucks with the axle load exceeding the allowable value made $16 \%$ (196041 vehicles) of all trucks.

- The highest axle load was 20,6 ton.

- According to the type of a vehicle, 55-class vehicles (i.e. a two-axle truck tractor with a threeaxle semi-trailer) most often had an excessive axle load (making $75 \%$ of all overloaded vehicles).

In the present paper, trucks which are the main vehicles having excessive axle load are considered from the perspective of their damage to road pavement.

The axle overload from 0,1 to 5,6 ton (registered in weighing) increases the detrimental effect on pavement from 0,08 to 11,12 as estimated by $E S A$. About $59,6 \%$ of all overloaded vehicles (including trucks with not allowable mass and axle load) exceed $E S A$ due to overloaded axles.

Overloaded axles (an axle takes $>10$ ton of mass) are typical of four-axle (34\%) and five-axle trucks which make $50 \%$ of all vehicles (with the total mass $>5,5$ ton). In weighing, the maximum vehicle mass of 54,2 tons and the maximum mass per axle equal to 15,6 tons were fixed. The effect of such an axle on the road pavement is evaluated as $E S A=13,38$. This is 3,4 times that produced by the maximum allowable $(115 \mathrm{kN})$ axle load $(E S A=3,95)$.

The allowable maximum mass of a three-axle truck and a two-axle semi-trailer is 18 tons, while the axle load is $60 \mathrm{kN} 2 \times 100 \mathrm{kN} 2 \times 90 \mathrm{kN}$ and the calculated allowable equivalent standard axle (ESA) is 7,77.

The heavier load has a higher detrimental effect on pavement, while the worn-out pavement increases the maintenance costs of vehicles. Therefore, the changes in the strength and roughness of pavement under the maximum axle loads of $100 \mathrm{kN}$ and $115 \mathrm{kN}$ were analysed. In calculations made on the road Vilnius-Kaunas-Klaipèda these initial data were used:

- $\quad$ average truck traffic per 24 hours during the testing period was 2990 vehicles;

- roughness of the considered road (IRI), (international road index) is $2,5 \mathrm{~m} / \mathrm{km}$;

- average modified strength coefficient of pavement structure (SNC) is 4,6;

- trucks make $15 \%$ of all vehicles on the route Vilnius-Kaunas-Klaipèda.

The calculations were made for $1 \mathrm{~km}$ of road in calculation under the conditions of various axle loads the emphasis was placed on the service life of pavement. The damage caused to the pavement by the recurrent axle load was calculated based on $W$. Patterson's model [4], taking into account pavement strength and environmental conditions.

For these calculations the scenarios described below were considered. Since the average flatness of the main road is rather high $(2,5 \mathrm{~m} / \mathrm{km})$, road surface is treated to increase this factor up to 1,7 in the above model. Then, road flatness decreases to the limiting value of 3,5 according to the regression equation and the overhaul (laying of an additional coating) is made to restore road flatness to 1,2 . Then, road flatness is decreased to the limiting value of 2,5 according to the regression equation and the surface of the pavement is treated again to increase the flatness to 1,7 according to this model. The regression of pavement continues according to the same model during the predicted period of 20 years.

The average savings on the maintenance costs of motor vehicles (MCMV) are calculated based on the distribution of the flow of vehicles (in per cent) and road roughness. Relative MCMV savings represent the difference between transport costs when calculations are based on $E S A_{10,0 \mathrm{t}}$ (maximum allowable axle load is $100 \mathrm{kN}$ ) and $E S A_{11,5 \mathrm{t}}$ (maximum allowable axle load is $115 \mathrm{kN}$ ).

The relationship between the deterioration rate and $E S A$ and traffic intensity, i.e. the number of cycles, is shown in Fig 1 by exponentials.

Given the number of load cycles of pavement and using the obtained curves, the value of $\operatorname{ES} A(x)$ correlating with pavement deterioration degree may be determined. The analysis of the above relationships has shown that for $E S A$ 35-40 pavement deteriora- 
tion of $20-40 \%$ has been achieved already after 10000 cycles. This factor should be taken into account maintaining and renovating the roads because proper maintenance can considerably prolong the service life of roads, as well as reduce maintenance and repair costs.

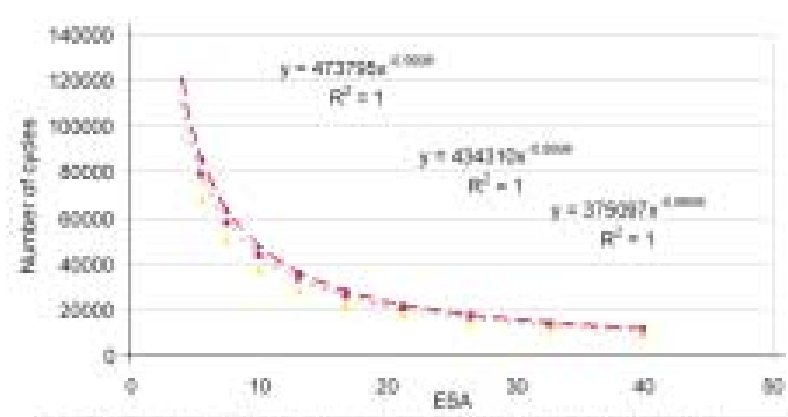

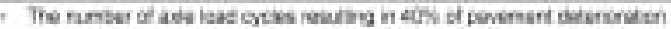

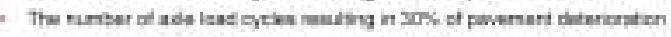

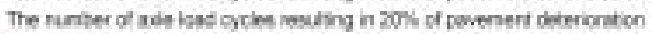

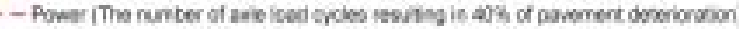

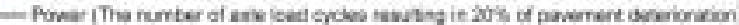

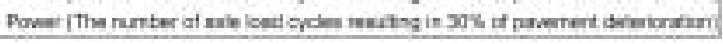

Fig 1. The relationship between the number of cycles and loading used in determining the deterioration of road pavement

Carriers infringing on traffic regulations and causing a higher damage to road pavement, should be penalized. The tax paid for exceeding the allowable axle load may be determined by the ratio of $E S A$ increase. The relationship between $E S A$ ratio (y) and payment for one kilometer run (x) is given in Fig 2.

As seen in the graph and in the analysis of the second power equation, the tax for axle overload is growing only a little more steeply than $E S A$ ratio. For example, $E S A$ ratio increase from 2 to 8 , i.e. by four times is accompanied by 4,4 times tax increase for one $\mathrm{km}$ run. Based on the graph represented in Fig 1 show-

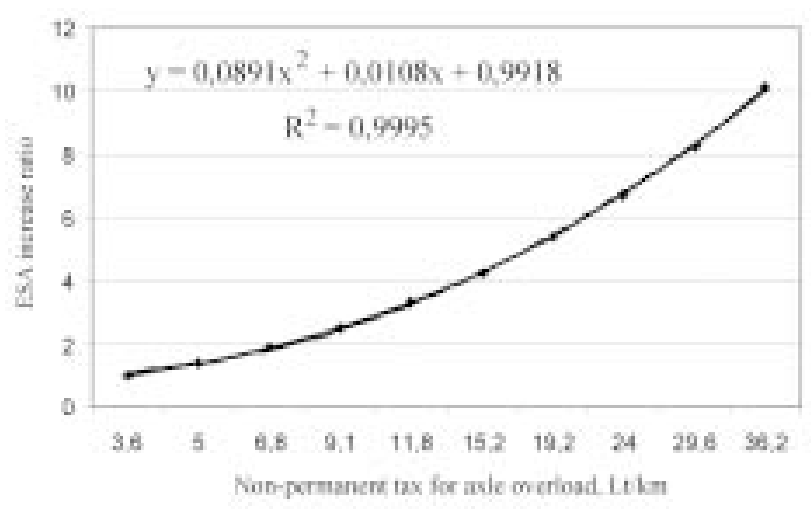

Fig 2. Payment for $1 \mathrm{~km}$ run depending on ESA ratio ing that highly increased loads lead to a considerable decrease of the number of load cycles resulting in complete deterioration of pavement, it may be stated that the considered tax is too small. The same applies to the tax imposed for one $\mathrm{km}$ run with the excessive axle

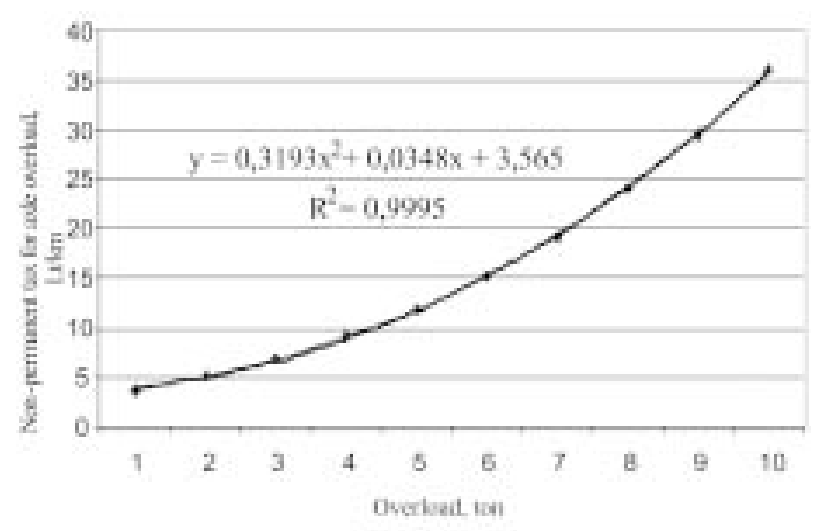

Fig 3. The relationship between tax, $\mathrm{Lt} / \mathrm{km}$, and exceeding of allowable load, ton

load depending on the direct axle overload (Fig 3).

Based on the methods of determining the damage caused by vehicles to road pavement discussed above in the present paper and the methods chosen to describe the damage caused by the deteriorated pavement to road vehicles [5], the regression equations for calculating maintenance costs of motor vehicles (MCMV) depending on the ride and the carried freight, Lt/ km, were generated.

$$
\begin{aligned}
& \text { When } E S A=1607(115 \mathrm{kN}) \\
& y_{1}=49,256 x+1131,1, \\
& R^{2}=0,9652,
\end{aligned}
$$

$$
\begin{aligned}
& \text { When } E S A=1210_{(110 \mathrm{kN})} \\
& y_{2}=49,828 x+1116,2, \\
& R^{2}=0,8693
\end{aligned}
$$

where $y_{1}, y_{2}$ denote MCMV, thous. Lt/ km; $x$ means years of employment of the road Vilnius-KaunasKlaipèda, 2000-2020.

Using equations (5) and (6), based on the statistical data on traffic flows and axle loads obtained for the period of five years, MCMV values for the coming years can be predicted. 


\section{Conclusions}

1. When $E S A=35-40$, about $40 \%$ of road pavement is deteriorated after 10-15 thous. of cycles.

2. When $E S A$ ratio was increased four-fold, the payment for overload increased only by 4,4 times.

3. For the proper maintenance of road pavement, more rigorous overload control and higher taxes for axle overload should be imposed.

4. The obtained regression equations $(5,6)$ allow maintenance costs in transport to be predicted, depending on the state of road pavement.

\section{References}

1. Report prepared by an OECD scientific expert group. Organization for economic co-operation and development (OECD) full-scale pavement test. Paris: Paris Cedex, 1991. $286 \mathrm{p}$.

2. Winfrey, R. Economic analysis of highways. International textbook company. Scranton. Pennsylvania, 1969. $116 \mathrm{p}$.

3. TKTI. Storing and updating the data on traffic flows on the main road of Lithuania. TKTI Report. Kaunas, 2006. $176 \mathrm{p}$.

4. Patterson, W. D. O.; Watanatada, T. Relationships between vehicle speeds, ride, quality and road roughness. In: Measuring road roughness and its effects on user cost and comfort. ASTM STP 884. American society of testing and materials. Philadelphia, 1985, p. 89-110.

5. TKTI. The revised programme of 2002-2015 for maintenance and development of the main Lithuanian roads for 2005-2015. TKTI Report. Kaunas, 2005. 